\title{
Experimental Study of Heat Transfer in a Container Filled with Water and Cooled by a Peltier Device
}

\author{
Hilmi Kuşçu, Kamil Kahveci \\ Trakya University \\ Mechanical Engineering Department, Trakya University, 22180 Edirne, Turkey \\ hilmi@trakya.edu.tr; kamilk@trakya.edu.tr
}

\begin{abstract}
Heat transfer in a cubical container filled with water and cooled by a Peltier device was investigated experimentally in this study. Hot surface of the Peltier device was cooled by a heat sink. Three temperature sensors were used in each direction in the container. The data measured by temperature sensors are send to an Arduino microprocessor in order to process data and send the results to an LCD screen and a computer to store the measurements. Results show that decrease in temperature inside the container is low in the early stage of cooling and it starts to increase as time progresses as a result of strengthening circulation. Results also show that temperature gets considerably lower values in the lower part of the container than that of the upper part. Results also indicate that temperature difference is low in the direction normal to the cooled surface. Finally, results indicate that heat transfer rate shows a decrease with time as the flow progressively approaches a steady state regime.
\end{abstract}

Keywords: Peltier device, thermoelectric cooling, temperature sensor, cubical container

\section{Introduction}

When an electric current is made to flow through a junction between two conductors, heat flux is generated at the junction. This phenomenon is known as Peltier effect. Accordingly, a Peltier or thermoelectric device transfers heat from one side of the device to the other side with consumption of electrical energy. The Peltier devices can be used as a heater or a cooler but they are mostly used in cooling applications. Efficiency of these devices are considerably lower than that of conventional compressor-based cooling systems. Peltier devices operate at about $10 \%$ efficiency, whereas efficiency of a compressor-based refrigerator is about 30\% [1]. On the other hand, they have a small size and weight and are highly reliable provided they are installed and used in an appropriate manner. Peltier coolers have a long lifetime exceeding 20 years. Peltier coolers have also no moving parts. This makes them vibration- and noise-free; therefore, they need less maintenance. Furthermore, as opposed to the conventional compressor-based cooling systems, Peltier devices do not require the usage of flammable or environmentally harmful refrigerants. Because of the aforementioned advantageous of Peltier devices over traditional cooling systems, they found a wide range of applications such as vehicle refrigerator, automobile seat cooler, portable picnic cooler, residential water cooler, computer microprocessor cooler [1-3]. A commonly used thermoelectric material in such applications is bismuth telluride $\left(\mathrm{Bi}_{2} \mathrm{Te}_{3}\right)$ as it is one of the most appropriate thermoelectric material around the room temperature. Alternating legs of p-doped and n-doped $\mathrm{Bi}_{2} \mathrm{Te}_{3}$ are connected electrically in series and thermally in parallel. In the p-doped legs, positively charged holes transport heat in the same direction as the current flow, and in the ndoped legs, heat is transferred in the opposite direction by negatively charged electrons [4]. The net outcome is that heat is transferred from the cold side to the hot side in both legs. Commercial coolers are generally composed of dozens of pairs of legs in order to maximize cooling power [4].

There is a limited number of studies in the literarure on thermoelectric cooling and on the performance of the systems using thermoelectric devices. Dabhi et al. [5] performed an analytical investigation on performance of thermoelectric refrigeration systems. They concluded that the COP increases up to a certain value with an increase in the current and then shows a decrease with a further increase in the current. Nogueira and Camargo [6] studied performance of an air conditioning system based on Peltier effect. They concluded that maximum temperature difference between the hot and cold surfaces of a Peltier device is one of the most important parameters in performance of an air conditioning system. Bian and Shakouri [7] investigated effect of inhomogeneous thermoelectric materials on cooling performance of a thermoelectric cooler. They found that cooling performance of a thermoelectric cooler increases significantly when an inhomogeneous thermoelectric 
material is used. Qian and Ren [8] investigated cooling performance of transverse thermoelectric devices and found that transverse refrigerators may propose higher cooling capacity with some compromise in efficiency when it is compared to their longitudinal counterparts. Palaniappan and Palanisamy [9] performed a numerical investigation on thermoelectric refrigeration system for two different thermoelectric material. Their results show that the heat absorbed by Bi-Te system is considerably higher than that of $\mathrm{Pb}$-Te system at ambient temperature conditions. Rabari et al. [10] investigated heat transfer in nanocomposite thermoelectric coolers. Results show that cooling performance increases a considerable amount if nanostuctered thermoelectric materials are used instead of conventional thermoelectric materials. Ahammed et al. [11] made an experimental investigation on thermoelectric cooling of electronic devices with a nanofluid in a multiport minichannel heat exchanger. Thire results show that thermal effectiveness of the cooling system increases with increase in volume concentration. Vian and Astrain [12] developed a heat exchanger for cold side of Peltier pellets in a thermoelectric refrigeration based on the principle of thermosiphon with phase change and capillary action. Their results show that cooling performance of thermoelectric refrigerators can be improved considerably by incorporation of the developed device. Najafi and Woodbury [13] conducted a numerical investigation on optimization of a cooling system based on Peltier effect for photovoltaic cells. Result shows that the photovoltaic cell temperature can be kept at a low level by a thermoelectric cooling with a reasonable amount of electrical energy consumption.

In this study, heat transfer in a cubical container filled with water and cooled by a Peltier device was investigated experimentally to reveal the performance of thermoelectric cooling.

\section{Material and Method}

The schematic view of the experimental setup used in this study is seen in Figure 1. The experimental setup consists of a container, a Peltier device with a heat sink, 27 temperature sensors, an Arduino microprocessor, an LCD screen and a computer. The container used in the study is a cubical container with dimensions of length $\mathrm{x}$ width $\mathrm{x}$ height:5.1 $\mathrm{cm} \mathrm{x} 4.8 \mathrm{~cm}$ $\mathrm{x} 4.8 \mathrm{~cm}$. PVC was used as material for the walls of the container except the cooled one in order to provide a good isolation. To guarantee the adiabatic boundary condition, walls were also covered by styrofoam of $1 \mathrm{~cm}$ thickness. Aluminum was used as material for the cooled wall to ensure a better heat transfer. The top wall of the container is open to atmosphere. The Peltier device (TEC1-12708 type) with a dimensions of $40 \mathrm{~mm}$ x $40 \mathrm{~mm} \times 3.5 \mathrm{~mm}$ was attached to the vertical aluminum wall of the container by a thermal silicone paste. The voltage and electric current of Peltier device with a cooling power of 66 watt are 12 volt and 5.5A amp. Heat is removed from the hot surface of the Peltier device by a hit sink. Therefore, the hot surface of Peltier device remains close to the ambient temperature. The temperature in different locations of the container (three in each direction, 27 in total) was measured by temperature sensors (DS1820 High precision 1-Wire). Temperature measurements with these temperature sensors are made using two bandgap-generated voltage sources [14]. One of the voltage sources has a high-temperature coefficient and changes deterministically across temperature. The other voltage source has a low-temperature coefficient and does not change across temperature [14]. An analog-to-digital converter (ADC) converts the difference between these two voltages to a digital value, representing the temperature of the device [14]. The resolution of the temperature conversion can be selected from 9 to 12 bits. The resolution in this study was selected as 12 bit. The accuracy of temperature measurements and conversion time depending on the resolution are given in Table 1 . The data measured by the temperature sensors are send to an Arduino microprocessor. The data of several temperature sensors are sent to the Arduino microprocessor with one cable with the scheme shown in Figure 2. The Arduino microprocessor used in this study is shown in Figure 3. The temperature data are send to the LCD screen and computer by the Arduino microprocessor. The computer is used to record the temperature data.

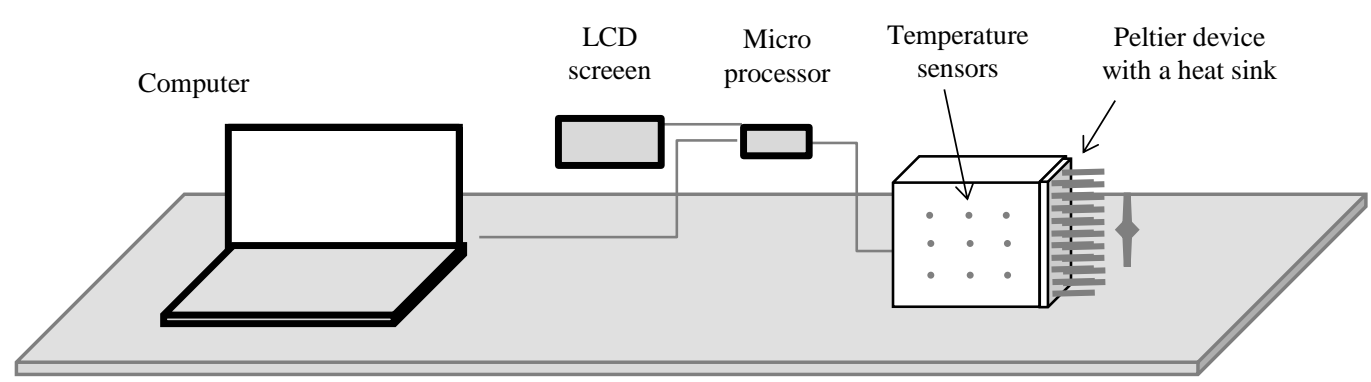

Fig. 1: Schematic view of the experimental setup. 
Table 1: Conversion times and resolution settings of the temperature sensors.

\begin{tabular}{|l|l|l|l|l|}
\hline Resolution & 9 bit & 10 bit & 11 bit & 12 bit \\
\hline Conversion Time $(\mathrm{ms})$ & 93.75 & 187.5 & 375 & 750 \\
\hline LSB $\left({ }^{\circ} \mathrm{C}\right)$ & 0.5 & 0.25 & 0.125 & 0.0625 \\
\hline
\end{tabular}

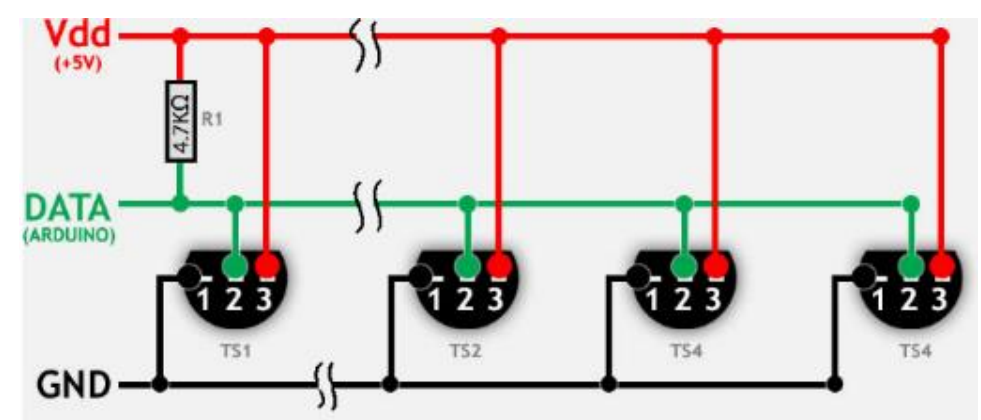

Fig. 2: Scheme used in the temperature data transfer process.
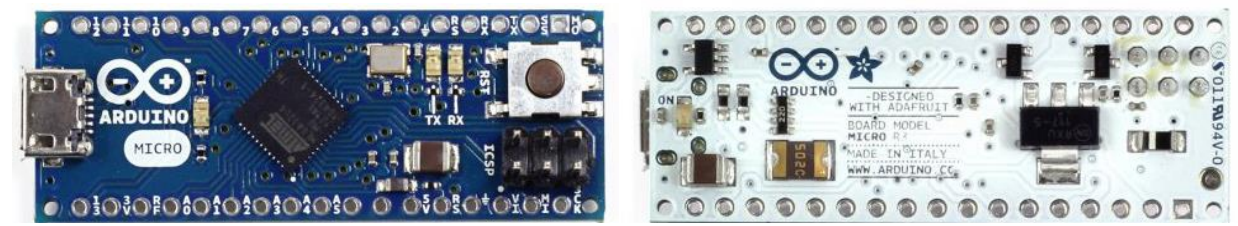

Fig. 3: Arduino microprocessor used in the study.

\section{Results and Discussion}

Heat transfer in a cubical container filled with water and cooled by a Peltier device was investigated experimentally by temperature measurements. The temperature measurements in container were made by equally spaced three temperature sensors in each direction as seen in Figure 4. The measurement results show that the temperature remains almost constant in the $\mathrm{z}$ direction as there is no a significant temperature gradient in the $\mathrm{z}$ direction as a result of adiabatic walls. Therefore, the results were given only for the various values of $\mathrm{x}$ and $\mathrm{y}$. Variation of temperature with time at different $\mathrm{x}$ locations is seen in Figures 5-7 for various values of distance along the y direction. As it can be seen from figures that decrease in temperature is low in the early stage of cooling as a result of weak buoyancy forces in this stage. As time progresses, temperature starts to decrease faster as a result of strengthening circulation in the flow field. Flow particles cooled by the Peltier device descend along the left wall of the container until they reach the bottom wall. Then they are shifted rightward along the bottom wall. Then, they begin to ascend until they reach to the top part of the container. Fluid particles on the top part of the container are shifted toward the left cold wall and their flow paths are completed. As it can be seen from figures that the temperature in the lower part of the container is lower than that of the upper part as the descending fluid particles along the cold wall of Peltier devise are cooled. As the distance from the cold wall increases, difference between the temperatures of fluid particles near the top and bottom part of the container decreases as the fluid particles get heated during their journey from cold wall to the right part of the container. As it can also be seen from figures that decrease in temperature slows down with time as the flow regime evolves toward the steady state regime.
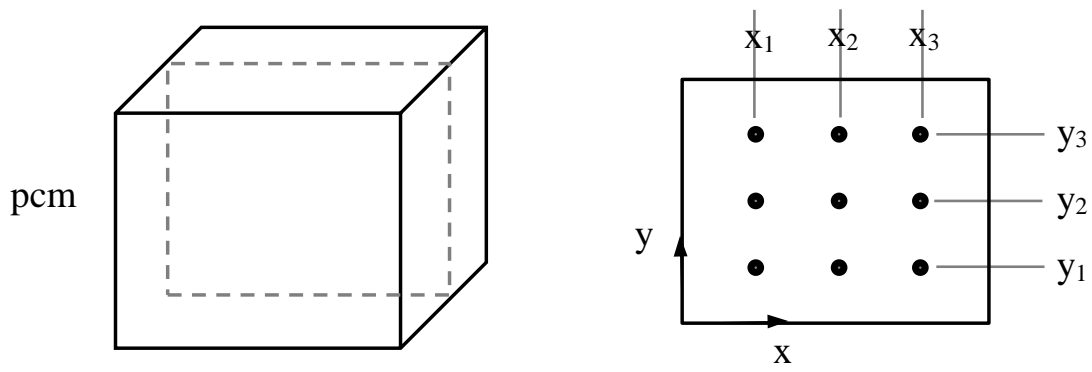

Fig. 4: Location of the temperature sensors in the container. 


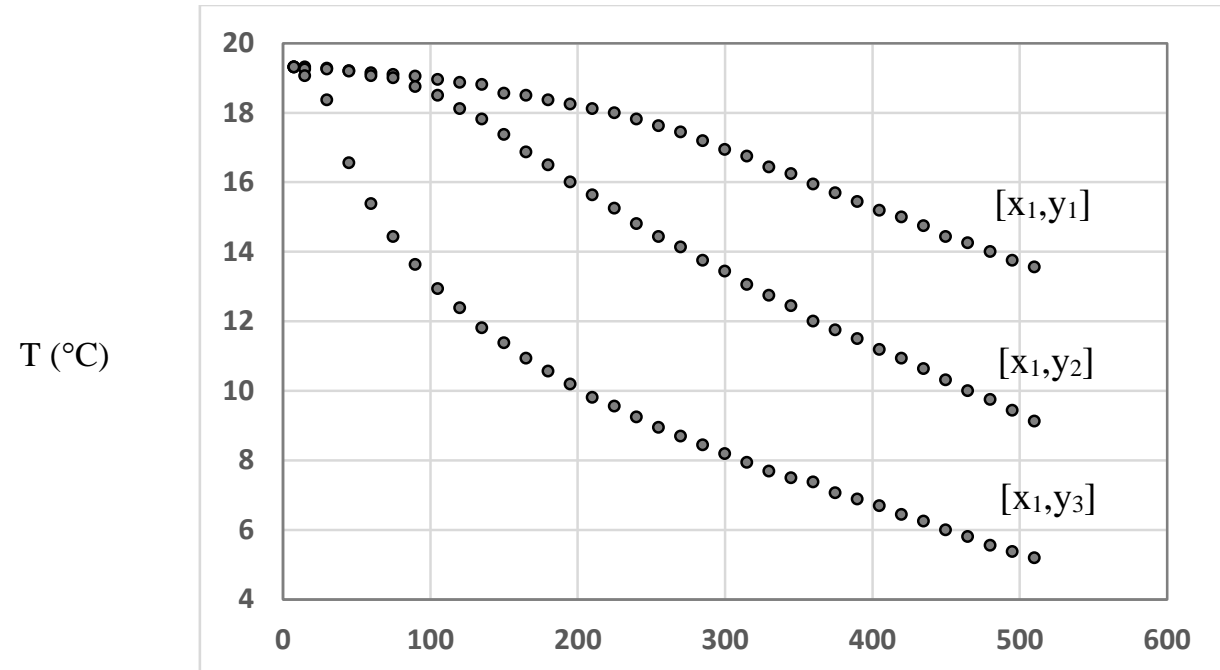

$\mathrm{t}(\mathrm{s})$

Fig. 5: Variation of temperature with time at $\mathrm{x}_{1}$ for various values of distance along the $\mathrm{y}$ direction.

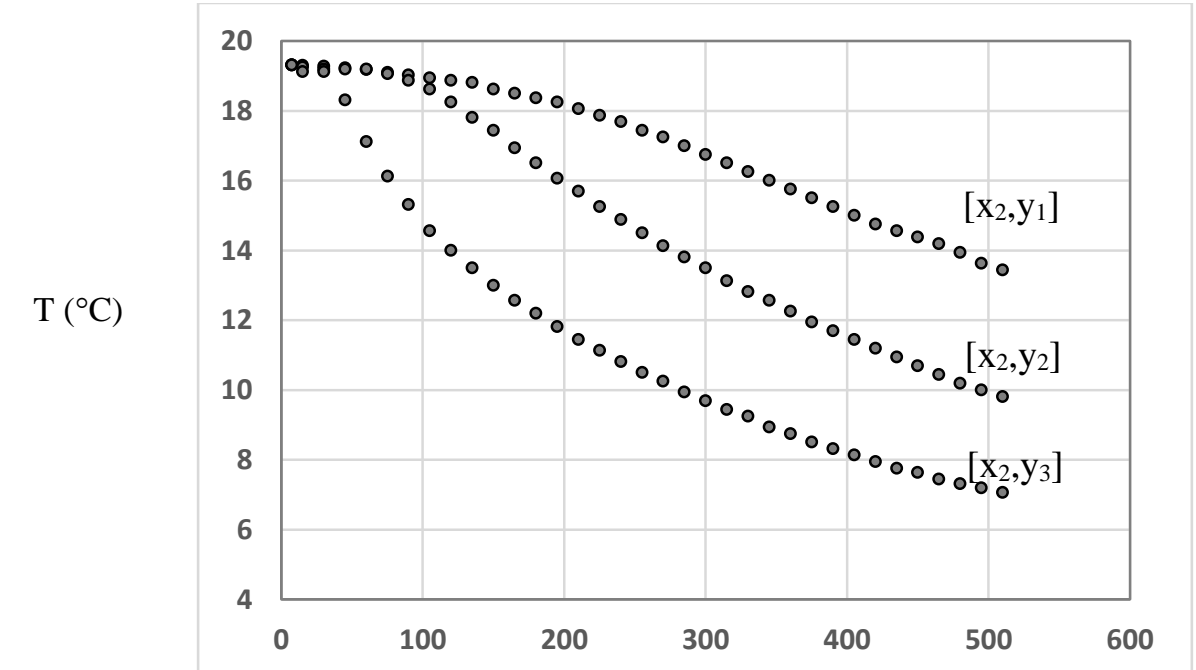

$\mathrm{t}(\mathrm{s})$

Fig. 6: Variation of temperature with time at $\mathrm{x}_{2}$ for various values of distance along the $\mathrm{y}$ direction.

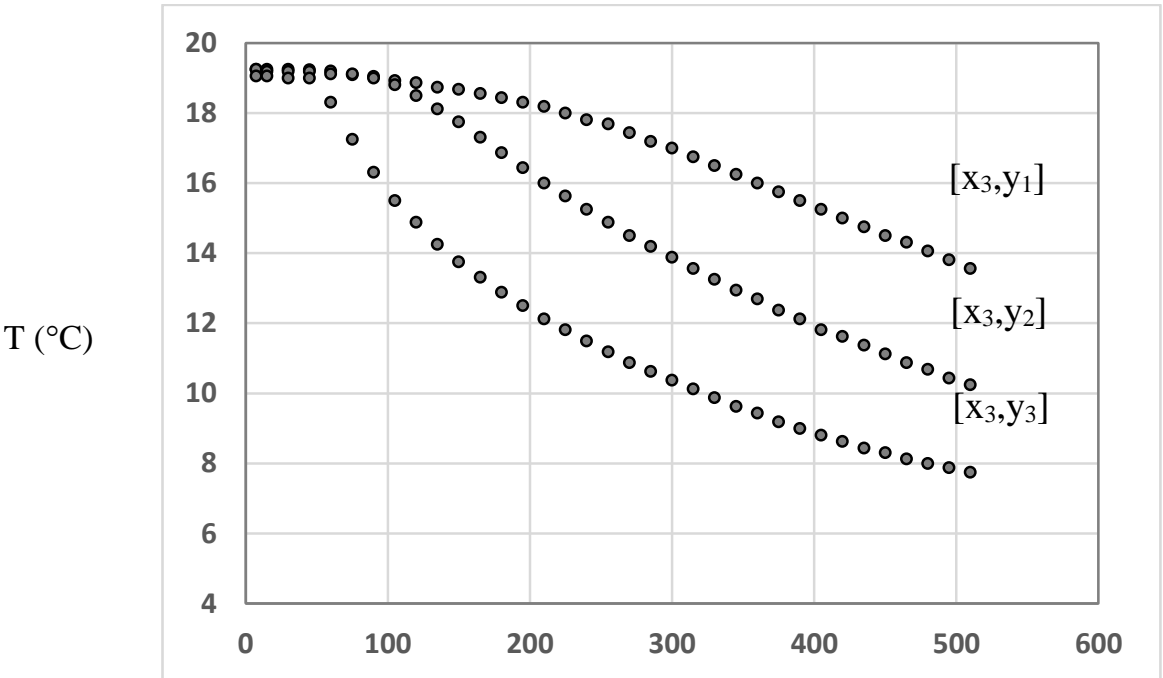

$\mathrm{t}(\mathrm{s})$

Fig. 7: Variation of temperature with time at $\mathrm{x}_{3}$ for various values of distance along the $\mathrm{y}$ direction. 
Variation of temperature with time at different y locations is seen in Figures 8-10 for various values of distance in the $\mathrm{x}$ direction. As it can be seen from figures that difference between the temperatures along the $\mathrm{x}$ direction is lower in the upper part of the container from that of the lower part. This can be attributed to the higher strength of circulation in the upper part of the container as a result of lower viscous forces and to the convective heat transfer from the top surface open to the environment.

Total heat transfer from the Peltier device to the container can be calculated approximately by the relation given below:

$$
Q=m C_{p}\left(T_{t=0}-T_{t, a v e}\right)
$$

where $\mathrm{Q}$ is the total heat transfer during the cooling process, $\mathrm{m}$ is the mass of the fluid and $\mathrm{T}$ is the temperature. Total heat transfer obtained based on the Eq. (1) is given in Figure 11. As it can be seen from figure that heat transfer rate to the container decreases with time as the heat transfer evolves to a steady state regime. When the steady state regime is attained, heat transfer from the Peltier device to the container will be equal to the heat transfer from the container to the environment. Heat transfer from the container to the environment is only from the top surface of the container open to the atmosphere as the all walls of the container except the wall cooled by Peltier device is adiabatic.

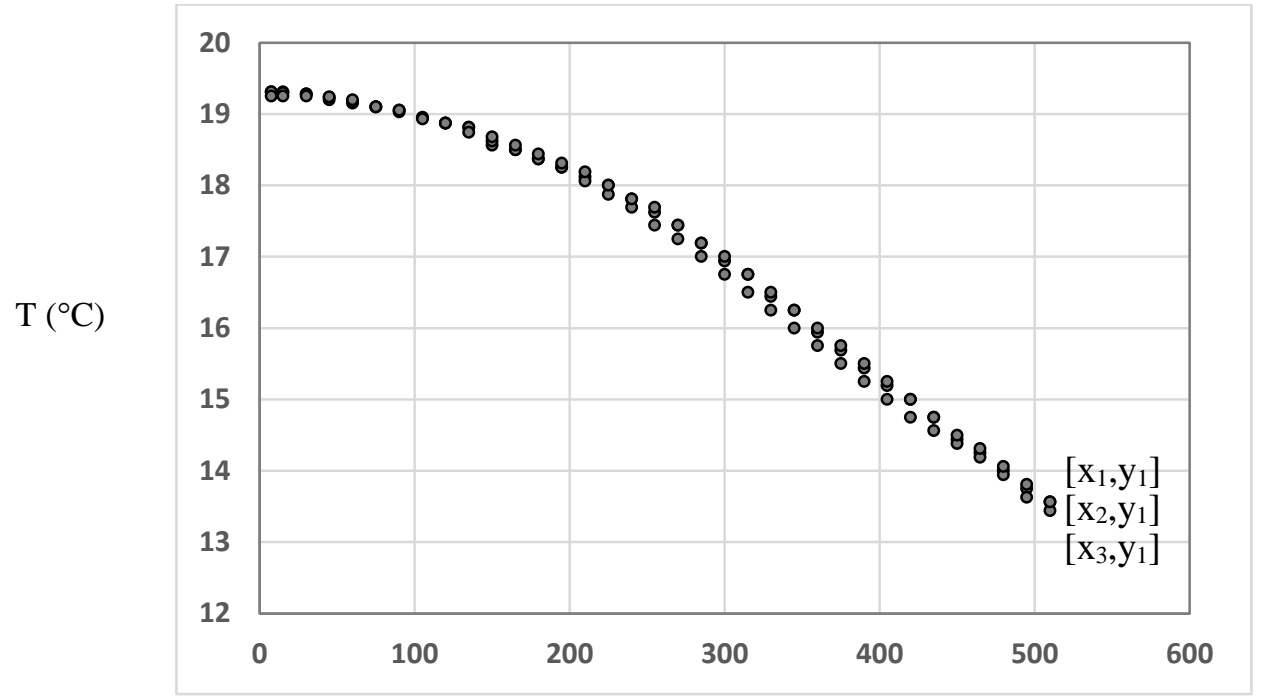

$\mathrm{t}(\mathrm{s})$

Fig. 8: Variation of temperature with time at $\mathrm{y}_{1}$ for various values of distance along the $\mathrm{x}$ direction.

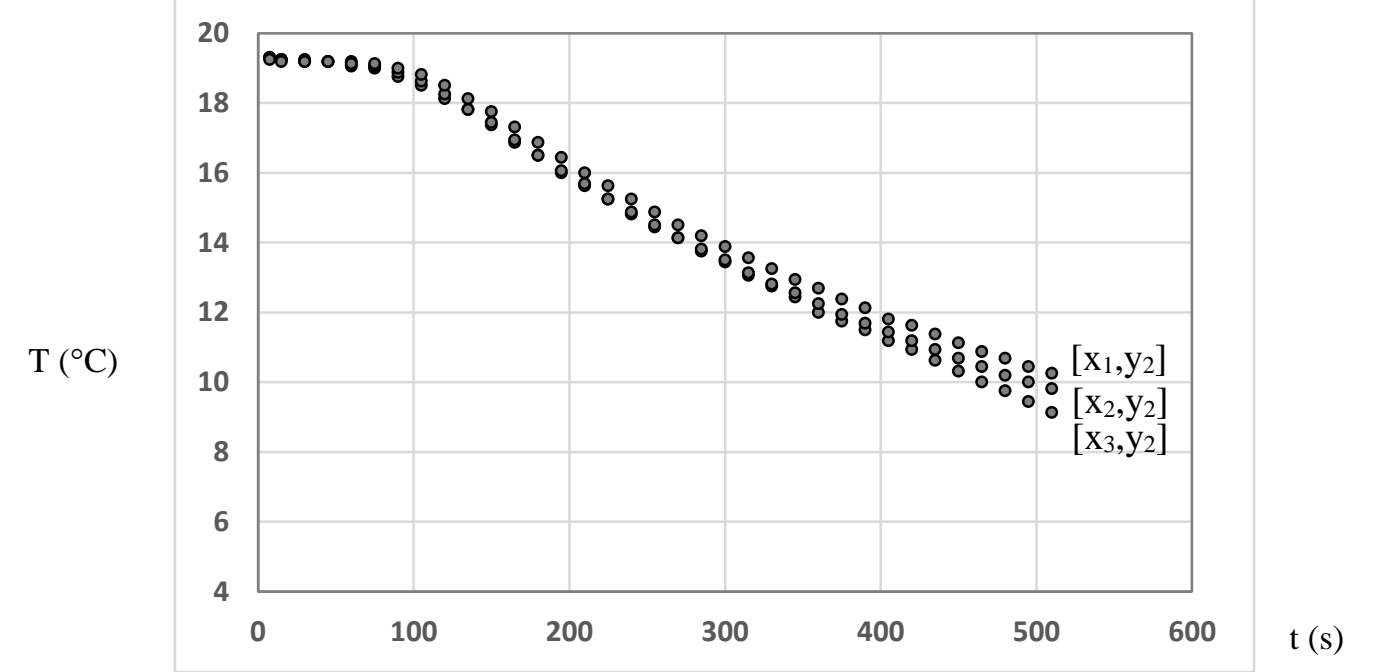

Fig. 9: Variation of temperature with time at $\mathrm{y}_{2}$ for various values of distance along the $\mathrm{x}$ direction. 


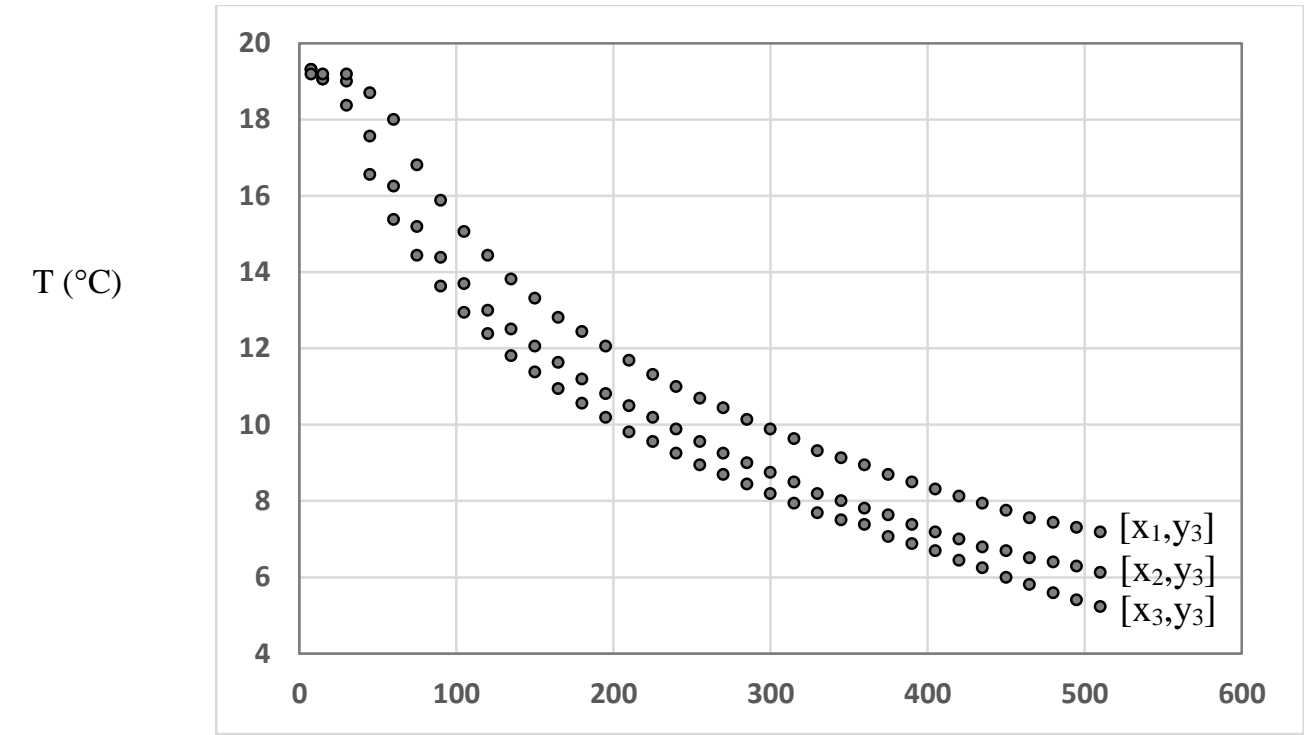

$\mathrm{t}(\mathrm{s})$

Fig. 10: Variation of temperature with time at $\mathrm{y}_{3}$ for various values of distance along the $\mathrm{x}$ direction.

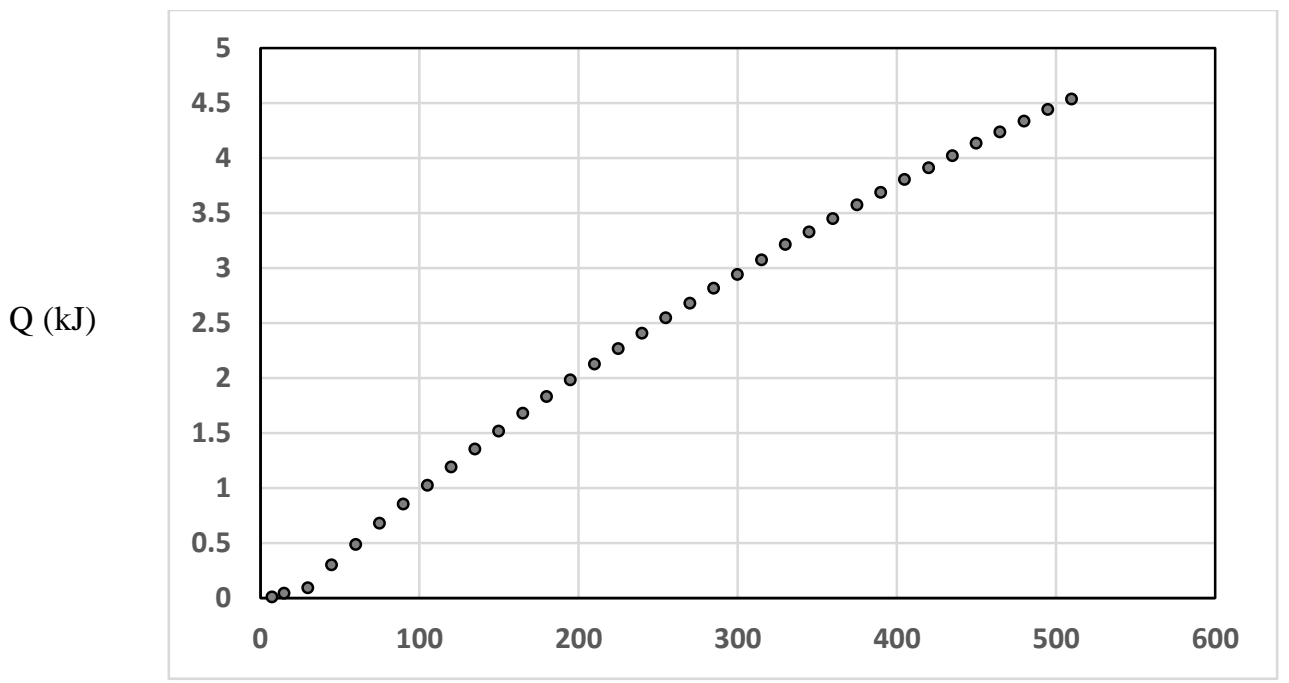

$\mathrm{t}(\mathrm{s})$

Fig. 11: Total heat transfer during cooling process by the Peltier device.

\section{Conclusion}

Heat transfer in a cubical container filled with water and cooled by a Peltier device was investigated experimentally in this study. The concluding remarks are as follows: Decrease in temperature inside the container is low in the early stage of cooling and it starts to increase as time progresses as a result of strengthening circulation. Temperature gets considerably lower values in the lower part of the container than that of the upper part. Temperature difference is low in the direction normal to the cooled surface. As the distance from the cold wall increases, difference between the temperatures of fluid particles near the top and bottom part of the container decreases. The difference between the temperatures along the $\mathrm{x}$ direction is lower in the upper part of the container from that of the lower part. Heat transfer rate shows a decrease with time as the flow approaches a steady state regime.

\section{References}

[1] Y. G. Gurevich and G. N. Lugvinov, "Theory of thermoelectric cooling in semiconductor structures," Revista Mexicana De Fisica, vol. 53, no. 5, pp. 337-349, 2007.

[2] F. J. DiSalvo, "Thermoelectric cooling and power generation," Science, vol. 285, pp. 703-706, 1999. 
[3] R. Venkatasubramanian, E. Siivola, T. Colpitts, and B. O'Quinn, "Thin-film thermoelectric devices with high room temperature figures of merit," Nature, vol. 413, pp. 597-602, 2001.

[4] B. S. Mann, "Transverse effects for cooling and heat flux sensing," MSc dissertation, Virginia Polytechnic Institute and State University, Blacksburg, Virginia, USA.

[5] J. B. Dabhi, N.B. Parmar, and N. S. Mehta, "Consideration for design of thermoelectric refrigeration system," International Journal of Advanced Engineering Research and Studies, vol. 1, no. 2, pp. 259-261, 2012.

[6] E. Nogueira and J. R. Camargo, "Performance analysis of a thermoelectric Air Conditioning," Rev. Clenc. Exatas, Taubate, vol. 9/10, pp. 9-11, 2003/2004.

[7] Z. Bian and A. Shakouri, "Cooling enhancement using inhomogenous thermoelectric materials," in Proc. Of ICT'06 25th International Conference on Thermoelectrics, Vienna, 2006, pp. 264-267.

[8] B. Qian and F. Ren, "Cooling performance of transverse thermoelectric devices, " International Journal of Heat and Mass Transfer, vol. 95, pp. 787-794, 2016.

[9] S. Palaniappan and B. Palanisamy, "Finite element analysis of thermoelectric system," Procedia Engineering, vol. 64, pp. 1056-1061, 2013.

[10] R. Rabari, S. Mahmud, A. Dutta, and M. Biglarbegian, "Analytsical and numerical studies of heat transfer in nanocomposite thermoelectric coolers," Journal of Electronic Materials, vol. 44, no. 8, pp. 2915-2929, 2015.

[11] N. Ahammed, L. G. Asirvatham, and S. Wongwises, "Thermoelectric cooling of electronic devices with nanofluid in a multiport minichannel heat exchanger," Experimental Thermal and Fluid Science, vol. 74, pp. 81-90, 2016.

[12] J. G. Vian and D. Astrain, "Development of heat exchanger for the cold side of a thermoelectric module," Applied Thermal Engineering, vol. 28, pp. 1514-1521, 2008.

[13] H. Najafi and K. A. Woodbury, "Optimization of a cooling system based on Peltier effect for photovoltaic cells," Solar Energy, vol. 91, pp. 152-160, 2013.

[14] (2016, March 14). Application note 4377. [Online]. Available: https://www.maximintegrated.com/en/appnotes/index.mvp/id/4377 